\title{
Equity Management Information Model of Collective Forest
}

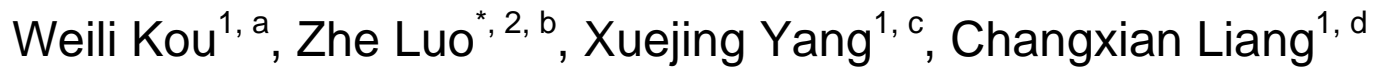 \\ ${ }^{1}$ School of Computer and Information, Southwest Forestry University, Kunming, Yunnan 650224, \\ China \\ ${ }^{2}$ Business School of Finance and Economics, Yunnan College of Business Management, Kunming, \\ Yunnan 650106, China \\ akwl_eric@163.com, bufokunming@qq.com, c283256287@qq.com, d1161598119@qq.com
}

Keywords: equity management, information model, collective forest

Abstract. Equity management with huge workloads is a time-consuming, costly, and labor-intensive work for administrators of forestry department. To enhance the work efficiency and improve management levels, this study presents an equity management information model of collective forest to improve work efficiency and management levels of forestry department. It supports functionalities of users' management, land patches management, stock assignment, holders management, and certificate management. Object-oriented programming method is employed to design and implement the system. The model was implemented and tested in the equity management work of Huidong County Sichuan Province, China. The study shows that informatization technology can enhance equity management efficiency and improve management levels. This study will transfer the model into internet environment and platform in the future.

\section{Introduction}

Collective forest and mountain forest are forests owned by collectivity. To ensure forestry sustainable development, protect ecosystem environment, and increase farmers' incomes, the government implemented the reform of collective forest property in China several years ago. With the completion of reform of collective forestry property right, equity management of collective forest lands becomes an important work of forestry department in the future for a long time. However equity management of collective forest is tedious and time-consuming, procedures of forestry land circulations are very complicated and excessively detailed. Informatization technology is an important way to enhance work efficiency and management levels of forestry department. It has already extensively applied to daily work or special missions related to forest management including forestry resources sharing, forestry program design, and reform of collective forest property right. At present, there is no mature information model and platform for equity management of collective forest. Thereby, this study attempts to apply advanced informatization and computer technology into equity management of collective forest for enhancing the work efficiency and management levels. This study aims to present a management information model of collective forest equity by combining business process and management characteristics of collective forest equity management.

\section{Background}

Forestry informatization plays an important role in modern forestry management. With the development of informatization and computer technology, new opportunities have emerged for 
forestry informatization development. How to apply these advanced informatization and computer technology for forestry management attracts lots of scholars and engineers all over the world. Reform of collective forest property right is an important policy made by Chinese government, which has already been implemented and accomplished in China several years ago. Under this policy, collective forest lands are divided into many equities and assigned them to farmers according certain rules. These equities can be sold, mortgaged, and transferred among farmers. Hence, how to effectively manage these equities becomes a difficult problem for administrators of forestry and related departments. To solve this problem, the study tries to present a management information model based on informatization and computer technology.

Development of forestry information system is complicated, long-term, and full of risks, which promotes the continuous development technology of information systems. Object-oriented method is a new programming paradigm and development technology of information systems, in which computer programs are designed by making them out of objects that interact with one another ${ }^{[1,2]}$. Object-Oriented Programming languages such as $\mathrm{C}++$, Java and Visual Basic were developed by computer scientists to speed programming and improve the quality of software. OOP software techniques break programs into functional blocks called objects, making frequently needed features such as control buttons, database management and math easier to use and share among programmers. The object-oriented programming is extensively used in information system designs and developments ${ }^{[3-7]}$. Since currently theory and technology of structure programming method is more mature than object-oriented, most of current forestry information systems are developed based on structure programming method, and few are based on object-oriented programming. With development of object-oriented method, more and more people accepted object-oriented methods to develop of forestry information systems. Introducing system development theory and method of object-oriented programming into forestry information system constructions is an advanced way for effective development of forestry information systems.

\section{Equity Management Information System of Collective Forest Design}

Design Principles. Design of equity management information system of collective forest must obey some design and implantation principles to ensure successful developments and applications of the system. Five main principles are followed: (1) Practicality. System functionalities should meet fundamental requirements of collective forest equity management. (2) Applicable. The system should be designed based on basic rules and workflows of forestry industry and business processes. (3) Generality. Other forestry departments with similar business processes can use the model without or minor revision. (4) Security. The system can prevent invasions by external illegal users, and leapfrog operations of administrators. (5) Friendly interfaces. An easy-to-use interface must be provided by the system for users to accomplish related tasks.

System Analysis and Functionalities. Equity management is an important aspect of the work of forestry department after reform of collective forest property right. The work includes querying, statistics, analysis, storage, print, certificates management, etc., and has characteristics of time-consuming, costly, and labor-intensive. Traditional management methods are not only inefficient but also error-prone, so a new management method is on urgent demands.

Based on equity management characteristics, five fundamental models (user management, land patches management, stock assignment, holders' management, and certificate management) are presented in this study (Fig. 1), include seven basic common functions (add, delete, update, query, statistics, and print, etc.). Besides these, user management includes roles and password management, such as creating a new role, changing user's password, assigning a certain role to a user, and so on. 
Land patches management includes patches merging, splitting, and auditing. Stock assignment includes allotment, change, and audit. Certificate management includes certificates issue, change, and revocation.

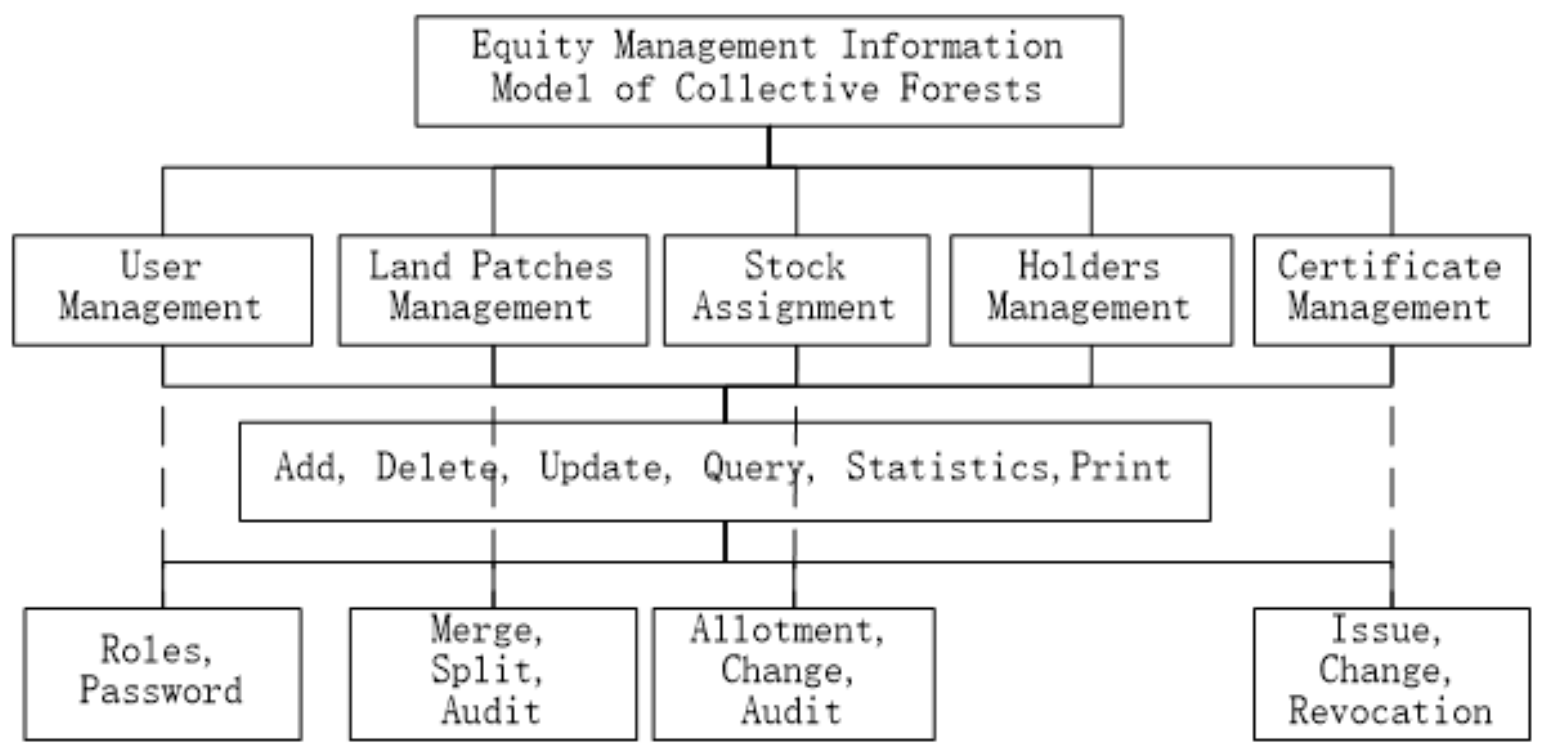

Fig. 1 Functionalities of equity management information system of collective forest

Database Design. Database design needs support data storage, business process, and system security of equity management of collective forest. The system needs to store the information of users, holders, certifications, land patches, equity, related assistant data, and others documents. Users and their roles information also must be supported in system database. Additionally, database design must meet the requirements of forestry data with huge a volume and frequent operations on them. Fig. 2 shows partial data tables of equity management information model of collective forest. Relational database management system was chosen in this study.

\begin{tabular}{|l|l|}
\hline \multicolumn{2}{|c|}{ Shares } \\
\hline PK & SR_ID \\
\hline & SR_CID \\
& SR_CountyName \\
& SR_CountyID \\
& SR_TownName \\
& SR_TownID \\
& SR_VillageName \\
& SR_VillageID \\
& SR_GroupName \\
& SR_GroupID \\
& SR_MeetingDate \\
& SR_PatchCount \\
& SR_TotalShares \\
& SR_StockRechuctionMannerID \\
& SR_IssueDate \\
& SR_XXCXID \\
& SR_XXCZGID \\
\hline
\end{tabular}
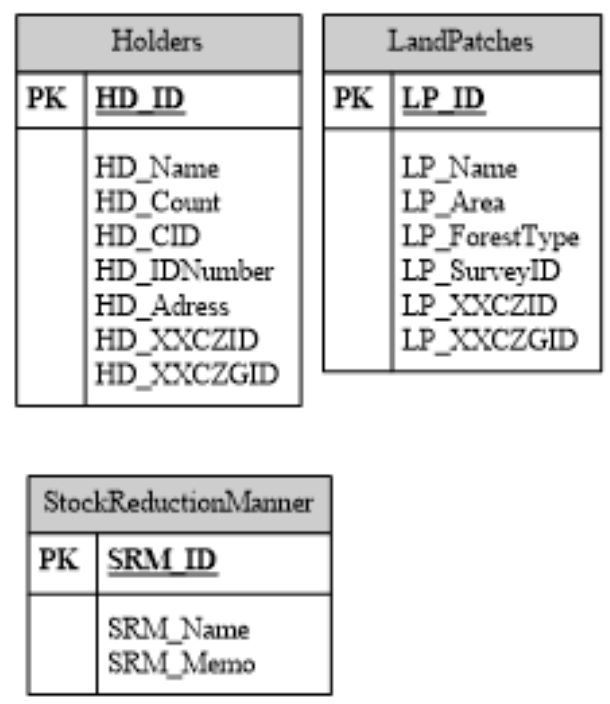

Fig.2 Partial data tables of equity management information model of collective forest

Classes Diagram. Class diagram expresses static structure of a model, including classes, their internal structures, and relations with other classes. According to the requirements of equity management work, six fundamental classes (Holders, Certificates, Shares, AdministrationAreas, 
StockReuctionManners, and LandPatches) were designed to implement the functionalities of the model (Fig. 3).

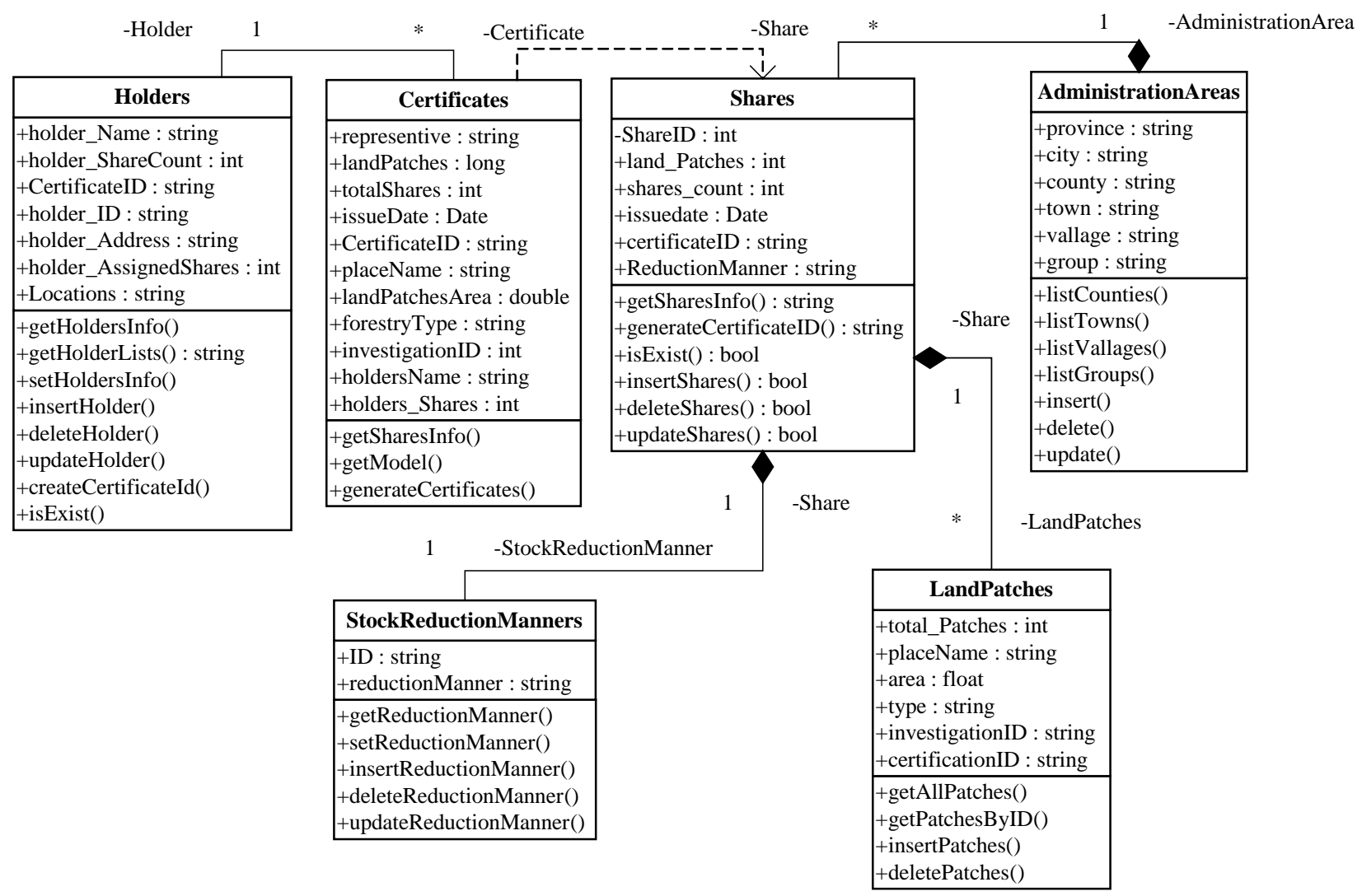

Fig. 3 The classes diagram

\section{Implementation and Applications}

This study takes object oriented programming paradigm to implement the equity management information model of collective forest. Because Visual Basic is a high level, visual, event-driven, and object oriented programming Language, this equity management information model of collective forest was implemented by Visual Basic programming language. Since spatial dataset of forestry data are stored in personal geo-database, which is based on Microsoft Access, so this study take Microsoft Access as the basic database management system. The model was applied in Huidong County Sichuan Province, China. Fig. 4 is an interface of the equity management information system of collective forest. The experiment result shows that the equity assignment and management of collective forest substantially enhanced work efficiency and management levels by taking informatization and computer technology. 


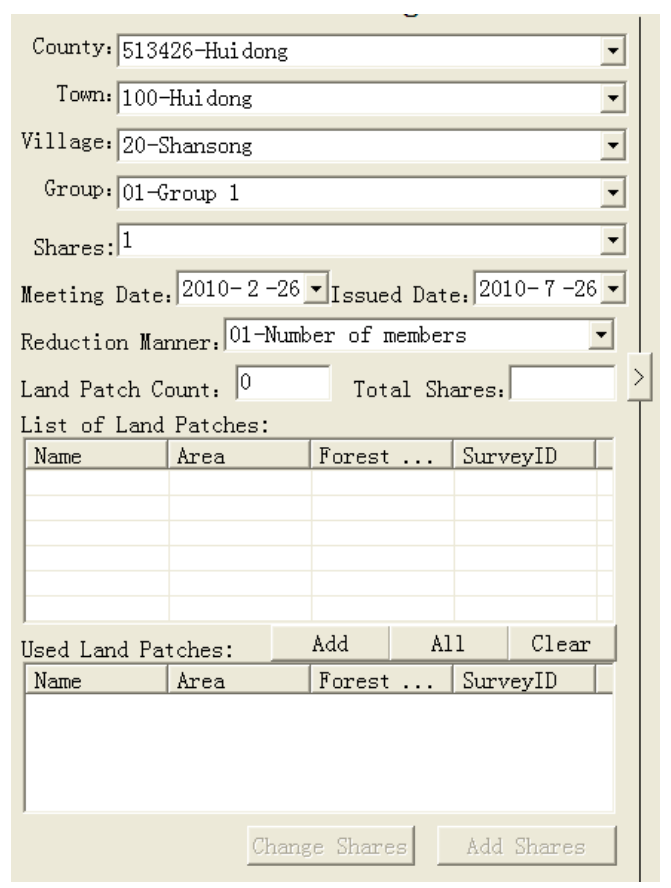

Fig. 4 An interface of equity management information system of collective forest

\section{Conclusions}

This study presented an equity management information model of collective forest. Based on characteristics of equity management of collective forest, fundamental modules were divided include equity assignment, equity revocation, certification creation, certification browse, holder management, user management, and so on. The model was implemented and tested in Huidong County, Sichuan Province, China. This study shows that informatization technology and computer technology can enhance work efficiency and management levels of equity management of collective forest. The model can be used in equity management work of other forestry department. In the future, this study will transfer the model into internet environmental and platform.

\section{Acknowledgement}

This work is supported by the National Natural Science Foundation of China (No. 31400493), the Yunnan Provincial Research Foundation for Basic Application Research, China (No. 2011FB070), the Natural Science Research Foundation of Education Bureau of Yunnan Province, China (No. 2011Y282), Supported by Research Center of Kunming Forestry Information Engineering Technology, and Teaching Research Foundation of Southwest Forestry University (No. YB201120).

\section{References}

[1] E. Kindler, I. Krivy,. Object-Oriented Simulation of Systems with Sophisticated Control. International Journal of General Systems. Vol. 40 (2011): p. 313

[2] John Lewis, William Loftus. Java Software Solutions: Foundations of Programming Design (6th edition). Pearson Education Inc. (2008) 
[3] Lingjun Luo, Rui Li. Land Information System with Object oriented Programming. Bulletin of Soil and Water Conservation. Vol. 13 (1998): p. 48

[4] Jun He, Zheng Zong, Yunsheng Liu. Journal of Tianjin Institute of Urban Construction. Vol. 13 (2007): p. 219

[5] H.G. Sol and K.M. van Hee. Using an Object-Oriented Diagram Technique for the Design of Inormation Systems. Dynamic Modelling of Information Systems, (2014): p. 121

[6] N. Sokolova, et al. Database Design for Information System of Neuroblastoma Development Forecasting based on the Object-Oriented Approach. Bulletin Kherson National Technical University, Vol. 1 (2012): p. 44

[7] Gilberto Câmara, Spring: Integrating Remote Sensing and GIS by Object-Oriented Data Modeling. Computers \& Graphics. Vol. 20 (1996), p. 395 